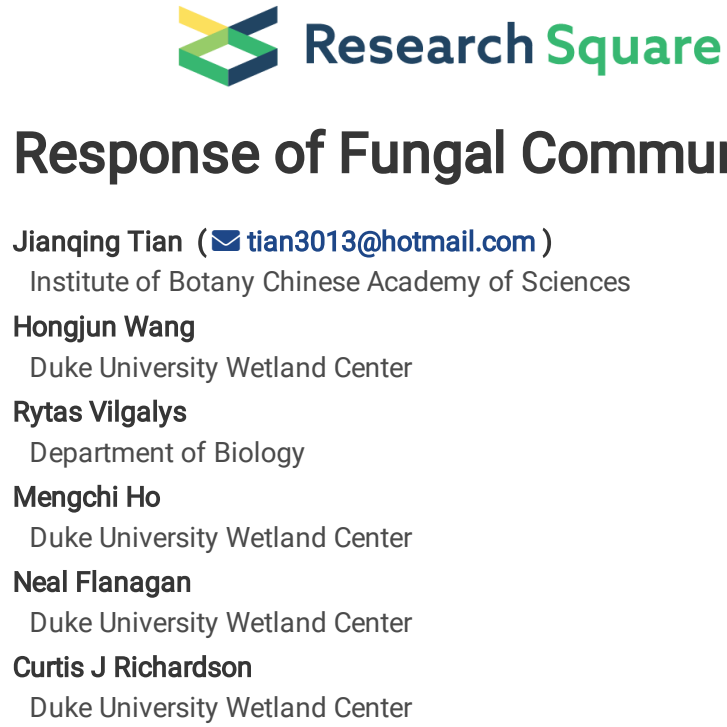

\title{
Response of Fungal Communities to Fire in a Subtropical Peatland
}

\section{Research Article}

Keywords: Archaeorhizomycetes, community assembly, depth-dependent, fire intensity, fire stage

Posted Date: February 15th, 2021

DOI: https://doi.org/10.21203/rs.3.rs-196967/v1

License: (c) (i) This work is licensed under a Creative Commons Attribution 4.0 International License. Read Full License

Version of Record: A version of this preprint was published at Plant and Soil on July 13th, 2021. See the published version at https://doi.org/10.1007/s11104021-05070-0. 


\section{Abstract}

Purpose: Wildfire, an increasing disturbance in peatlands, could dramatically change carbon stocks and reshape plant/microbial communities, with longlasting effects on peatland functions. Soil fungi are important in controlling the belowground carbon and nutrient cycling in peatlands; however, the impact of altered fire regimes on these fungi is still unclear.

Methods: Here we assessed fungal abundance, composition, and diversity across four soil depths $(0-5 \mathrm{~cm}, 6-10 \mathrm{~cm}, 11-15 \mathrm{~cm}, 16-20 \mathrm{~cm})$ under lowintensity and high-intensity fire in a subtropical peatland in the southeastern USA.

Results: Low-intensity fire significantly increased fungal Shannon diversity and the saprotrophic fungal composition in the $0-5 \mathrm{~cm}$ soil layer immediately and then retracted within 2 years. Such hump-shaped pattern, however, were not observed in deeper soils. The dominant fungal class Archaeorhizomycetes declined initially and then returned to pre-low-intensity fires levels at $0-5 \mathrm{~cm}$ depths. Time since low-intensity fire was a primary driver of fungal composition in the $0-10 \mathrm{~cm}$ soil depth, while geographical distance among sites affected the deeper soils $(11-20 \mathrm{~cm})$. The fungal Shannon diversity failed to recover to the unburned state even after 30 years after high-intensity fire, especially in 6-20 cm soil depths. Stratification patterns of the fungal community was diminished by high-intensity fire. Soil properties (either phenolics or carbon) were the primary drivers in shaping fungal community reassembly after highintensity fire across all soil depths.

Conclusion: Collectively, the fungal communities seem to be highly resilient to low-intensity fire, but not to high-intensity fire in our shrub bog peatlands.

\section{Introduction}

Peatlands store one third of global soil carbon, with a significant portion of this carbon mass (10-30\%) stored in low-latitude regions (Dargie et al. 2017; Turetsky et al. 2002; Turetsky et al. 2015). Fire is an important natural disturbance in peatlands (Pellegrini et al. 2018; Whitman et al. 2019), and its regimes have been shifting in face of rising temperatures and more drought events resulting from climate change and human activities (Ali et al. 2012; Langner and Siegert 2009; Turetsky et al. 2015). For example, some low-latitude fire-resistant peatlands became fire-prone over the last decade due to high-frequency lowintensity fires and occasional high-intensity fires (Cole et al. 2019; Turetsky et al. 2015). Fire intensity and frequency changes may have cascading consequences for long-term carbon dynamics in peatlands (Kettridge et al. 2015; Pellegrini et al. 2018; Turetsky et al. 2015). Therefore, it is critical to understand the consequence of fire regimes for ecosystem structure, function and dynamics (Pressler et al. 2019), especially in low-latitude peatlands.

Microbes play a central role in soil carbon turnover (Sun et al. 2015; Winsborough and Basiliko 2010), and their responses to fire may substantially influence peatland recovery after fire (Allison and Martiny 2008). Fungi, as predominant peat decomposers, principally moderate decomposition and nutrient cycling in peatlands (Phillips et al. 2013). Most studies have assessed the effects of high-intensity/high-severity fires on the fungal community, which cause large declines in fungal biomass and result in fungal community shifts (Dooley and Treseder 2012; Holden et al. 2013; Semenova-Nelsen et al. 2019). Although devastating peat-consuming high-intensity wildfires have been increasing due to current climate change, the majority of fire in peatlands are low-intensity (Boby et al. 2010; Turetsky et al. 2015), which actually benefit carbon accretion in some peatlands (Flanagan et al. 2020). High-intensity wildfires tend to have greater impacts and longer lasting effects than low-intensity fires due to fire-induced tree mortality and deep soil combustion. Previous studies showed that high-intensity wildfire had negative effects on soil fungal diversity (Day et al. 2019; Hernandez-Rodriguez et al. 2013; Holden et al. 2013; Martin-Pinto et al. 2006), while some studies found increasing fire severity generally had neutral effects on fungal community in boreal wetlands (Whitman et al. 2019). Xiang et al. (2015) found both low- and high-intensity fire had similar negative effects on fungal alpha diversity.

Fires also modify soil fungal communities and could take years to return to a pre-fire structure, possibly impacting ecological functions in these low-nutrient peatlands, such as carbon sequestration (Clemmensen et al. 2015), ectomycorrhizal colonization of plants (Treseder et al. 2004) and decomposition rates (Holden et al. 2013). An understanding of the effect of time-since-fire on fungal community is therefore required to provide a foundation for investigation of long-term fire intensity effects on the soil fungal community. Intensity of fire and fungal community legacies could impact fungal community fire return interval. For example, low-intensity prescribed fire have been reported that have a minimal or no effect on microbial community (Kranz and Whitman 2019; Oliver et al. 2015), while fungal communities required at least 24 years to return to pre-fire levels after high-intensity fire (Holden et al. 2013). Resistant fungi might exhibit a neutral response to a light perturbation and maintain their biomass, abundance, and composition, while resilient communities may change a little and return to their original structure shortly (Allison and Martiny 2008) after low-intensity fire. Different fungal species or functional groups also have various recovered timescale. Ectomycorrhizal and saprobic fungi differ in their recovery to pre-fire levels (Holden et al. 2016; Treseder et al. 2004; Yang et al. 2020). In this context, understanding the influence of variations in fire intensity on fungal community are important for predicting microbial feedbacks to carbon accumulation in fire-frequented ecosystems.

The heat penetration and organic matter loss vary with depth during fire, where the top horizon will be more affected than lower horizons by fire (Certini 2005). Few studies indicate a depth-dependent response pattern with a stronger response of soil fungal communities to wildfire (i.e., high-intensity fire) in the top horizon than in lower horizons, at least in boreal and cold-temperate forests (Holden et al. 2013; Yang et al. 2020). While Kranz and Whitman (2019) reported that low-intensity fire had no effect on bacterial community across all horizons, but they did not assess the fungal community. The degree of soil heating and organic matter combustion is also dependent on the fire intensity (Kranz and Whitman 2019), which would cause a divergent response pattern of fungal communities in different soil depths to fire intensity. However, these relationships are largely unknown. A recent study did show that the response pattern of soil carbon accumulation to fire was depth and fire-intensity dependent (Sawyer et al. 2018).

Due to increasing shrub and tree encroachment in boreal peatlands (Turetsky et al. 2015), understanding the response of fungi to changes in fire regimes in low-latitude shrub peatlands has significant global implications. Here, we study the response of fungi to low-intensity fire and high-intensity fire in an ericaceous shrub peatland in Pocosin Lakes National Wildlife Refuge (PLNWR), North Carolina, USA (Figure S1). The shrub species in pocosins are similar in

Page $2 / 18$ 
physiognomy to the expanding ericaceous shrubs found in many drained Sphagnum peatlands in boreal areas (Bragazza 2006; Bragazza et al. 2013). However, studies of fungal community as a function of time since fire in low-latitude shrub peatlands are relatively rare.

In this study we address three questions: 1) how does fire intensity alter soil fungal community composition, diversity, and abundance? 2) does the recovery of the fungal community vary with fire intensity? and 3) does depth-dependent fungal community have a fire intensity-based divergent response pattern? We hypothesized that fungi are highly resilient to low-intensity fire as fungi possess heat-resistant structures (Greene et al. 2010), or can survive in spore banks (Glassman et al. 2016). While fungal community may lose their resilience under high-intensity fire due to high temperature and destruction of the organic matter (Barcenas-Moreno and Baath 2009). We further postulated that low-intensity fires may have stronger effects on surface soil than subsoil fungal communities, while high-intensity fire may reset fungal communities and diminish the fungi stratified pattern in peatlands. It has been found that low-intensity fire only burn the top few centimeters of the soil surface and samples that are taken down to greater depths may dilute the signal of the response of soil microbial communities to fire (Neary et al. 1999). High-intensity fire can consume entire organic horizons leaving large ash deposits (Hammill and Bradstock 2006). Nutrients derived from ash that percolate into the soil (Sawyer et al. 2018) are likely to homogenize the accessible substrate for the fungal community, which may, in turn favor a similar fungal community down soil depths

\section{Materials And Methods Study Sites and Prescribed Burn}

The study site is in a shrub bog at the Pocosin Lakes National Wildlife Refuge, North Carolina, USA $\left(35^{\circ} 37^{\prime}-35^{\circ} 44^{\prime} \mathrm{N}, 76^{\circ} 27^{\prime}-76^{\circ} 35^{\prime} \mathrm{W}\right)$. Dominant plant of study area included Ilex glabra, Pinus taeda, Woodwardia virginica and Vaccinium formosum. The mean annual temperature is $16.8^{\circ} \mathrm{C}$, and mean annual rainfall is $1,230 \mathrm{~mm}$. A prescribed fire took place on Pungo North and Pungo South $(2000 \times 800 \mathrm{~m})$ in March 2015 . To characterize the temperature and duration of prescribed fire in peatlands, we monitored soil temperatures at the surface of litter (litter charred but not the peat soil beneath) during a prescribed fire. The prescribed fire displayed a rapid consumption of aboveground biomass by fire, and soil surface temperatures reached a peak temperature of $450{ }^{\circ} \mathrm{C}$ within 3 minutes and then dropping below $60^{\circ} \mathrm{C}$ within ten minutes after the fire front passed (Flanagan et al. 2020), therefore, we classified this prescribed fire event as low-intensity fire. Soils were collected before fire samples (i.e. undisturbed sample, UD), 15 days post-low-intensity-fire (15d) and 71 days post-lowintensity-fire (71d) from Pungo North and Pungo South as low-intensity fire samples. One adjacent plot experiencing similar low-intensity prescribed fire with 2 years post-low-intensity-fire (2y) was also collected as low-intensity fire samples. Based on fire records, two other sites with more than 1-meter of peat burned 30 years ago and 5 years ago were selected for high-intensity fire sampling, respectively. We collected samples from those two sites (5y and $30 \mathrm{y}$ ) as high-intensity fire samples (Figure S1). The distance between those five sites ranged from $0.25 \mathrm{~km}$ to $3.3 \mathrm{~km}$. We took triplicate soil cores at each site (with a distance $>10 \mathrm{~m}$ from each other), and each soil core was sliced to four sub-samples $(0-5 \mathrm{~cm}, 5-10 \mathrm{~cm}, 10-15 \mathrm{~cm}, 15-20 \mathrm{~cm})$. We recorded shrub diversity in each plot. A total of 108 soil samples ( 4 depths $\times 3$ cores $\times 9$ site-fire time $=108$ ) were collected. Soils were transported to the laboratory on ice. Half of the samples were frozen at $-80^{\circ} \mathrm{C}$ for DNA isolation; the rest were stored at $4{ }^{\circ} \mathrm{C}$ for chemical analysis. Climate and some basic information of each site (based on different fire history) was summarized in Table S1.

\section{Soil Chemistry Analysis}

Deionized water-extraction of fresh soil was used for dissolved organic carbon (DOC) and total soluble phenolics measurements. DOC was determined as the difference between total $\mathrm{C}$ and inorganic $\mathrm{C}$ by a total $\mathrm{C}$ analyzer (Shimadzu 5000A, Kyoto, Japan). Following the Folin-Ciocalteu procedure, soluble phenolics were measured. Inorganic nitrogens $\left(\mathrm{NH}_{4}-\mathrm{N}\right.$ and $\mathrm{NO}_{3}-\mathrm{N}+\mathrm{NO}_{2}-\mathrm{N}, 2 \mathrm{M} \mathrm{KCl}$ extraction) were determined colorimetrically on a flow-injection analyzer (Lachat QuikChem 8000, Milwaukee, WI, Wisconsin, USA). Total carbon and nitrogen in soil were analyzed by a combustion CN soil analyzer equipped with a TCD detector (ThermoQuest Flash EA1112, Milan, Italy).

\section{DNA Extraction and Sequencing}

Genomic DNA was extracted from $0.25 \mathrm{~g}$ (fresh weight) of each homogenized soil sample using the PowerSoil DNA isolation kit (Mo Bio Laboratories, Carlsbad, CA, USA), according to the manufacturer's instructions.

A two-step PCR modified from Lundberg et al. (2013) was used for DNA amplification. The fungus-specific primers ITS1F and ITS4 (White et al. 1990) were used. In the first step, primer constructs were used, which included a frameshift section (six per gene region), a linker section recognized in the second step, and gene specific sequences. The reaction condition was $95^{\circ} \mathrm{C}$ for $10 \mathrm{~min}, 30$ cycles at $95^{\circ} \mathrm{C}$ for $1 \mathrm{~min}, 50^{\circ} \mathrm{C}$ for $1 \mathrm{~min}, 72^{\circ} \mathrm{C}$ for $1 \mathrm{~min}$, and $72{ }^{\circ} \mathrm{C}$ for $10 \mathrm{~min}$. The second step ligated MID tags, incorporating a linker region recognizing that used in the first step and Illumina adaptor sequences. The reaction condition was $95^{\circ} \mathrm{C}$ for $10 \mathrm{~min}, 5$ cycles at $95^{\circ} \mathrm{C}$ for $1 \mathrm{~min}, 63^{\circ} \mathrm{C}$ for $1 \mathrm{~min}, 72^{\circ} \mathrm{C}$ for $1 \mathrm{~min} 20 \mathrm{~s}$, and $72{ }^{\circ} \mathrm{C}$ for 10 min. A PCR negative control was performed with sterile $\mathrm{H}_{2} \mathrm{O}$ as template. The amplicon concentration of each sample was determined after purification using Qubit ${ }^{8}$ 2.0 Fluorometer (Invitrogen, Grand Island, NY, USA). Samples were pooled at equimolar concentrations, purified using AMPure Bead cleanup, and submitted to the core facility at Duke University (Durham, NC, USA) for sequencing using Illumina MiSeq (Illumina, San Diego, CA, USA). The sequence data of 30y sites and before-fire sites were retrieved from another of our papers (unpublished, accession number SRP122579). Sequence data obtained from this study has been deposited in the NCBI Sequence Read Archive (SRA) with the accession number SRP176379.

\section{Quantitative PCR}


Quantitative PCR (qPCR) was performed to estimate the abundances fungi in soil samples. Fungi were targeted with ITS1f (5'-TCC GTA GGT GAA CCT GCG G$3^{\prime}$ ) and 5.8s (5'-CGC TGC GTT CTT CAT CG-3') primer pair (Fierer et al. 2005). Each 25- $\mu$ reaction mixture contained $12.5 \mu$ of SYBR ${ }^{\text {TM }}$ Green PCR Master Mix (ThermoFisher Scientific, MA, USA), $9.5 \mu$ of PCR water (Mo Bio Laboratories), $1 \mu$ l of each of the primers $(10 \mu \mathrm{M})$, and $1 \mu$ l of isolated DNA as the template. The conditions were $15 \mathrm{~min}$ at $95^{\circ} \mathrm{C}$, followed by 40 cycles of $95^{\circ} \mathrm{C}$ for $1 \mathrm{~min}, 53^{\circ} \mathrm{C}$ for $30 \mathrm{~s}$, and $72{ }^{\circ} \mathrm{C}$ for 1 min. Calibration standards and negative controls were included on each plate in triplicate. A plasmid standard containing ITS region was generated using DNA extracted from pure culture strain. Genomic DNA was sourced from a Aspergillus sp. isolate. The amplification of ITS region was cloned using the TOPO TA cloning kit (Invitrogen). Plasmids were isolated using the Qiaprep Plasmid Miniprep kit (QIAGEN, Valencia, CA, USA) with DNA concentrations determined by Qubit ${ }^{8} 3.0$ Fluorometer (Invitrogen, Grand Island, NY, USA). Calibration standard curves were generated using triplicate 10-fold dilutions of plasmid DNA. We used at least three nonzero standard concentrations per assay. Target copy numbers for each reaction were calculated from the standard curves, assuming that the average molecular mass of a double-stranded DNA molecule is $660 \mathrm{~g} \mathrm{~mol}^{-1}$.

\section{Bioinformatics}

ITS sequences were quality filtered and processed using the standard QIIME pipeline (Caporaso et al. 2010). All sequences were demultiplexed into samples based on unique identification barcodes using the split_libraries_fastq.py script with a quality score less than 20. As ITS1f and ITS4 are too long to pair-end, the sequences from both primers were processed separately. Sequences were sorted by gene region and primers were removed using cutadapt, and then reads were trimmed to $220 \mathrm{bp}$ using -fastq_filter with a q10 minimum value as a quality filter. Sequences were dereplicated and singletons were removed. The ITS1 and ITS2 region from the remaining sequences was identified and extracted using the fungal ITSx software (Bengtsson-Palme et al. 2013). The extracted sequences were binned into operational taxonomic units (OTUs) at 97\% match using USEARCH (Edgar 2010). OTUs were classified taxonomically using a QIIME-based wrapper of BLAST against the UNITE database (Abarenkov et al. 2010) as a reference, and a BLAST e-value $<1$ e was a criterion for matching. Taxonomic-based alpha diversity was calculated as Chao1 index (richness) and Shannon's diversity index $(H)$. All singleton OTUs were excluded from the dataset. The results from both primers reads were similar (Figure 1 and Figure S2), thus libraries from ITS1f reads were used for further analysis of fungal communities. In order to analyze fungal diversity and composition at the same sequencing depth, samples were rarefied for the further analysis.

Using the FUNGuild algorithm, fungal OTUs were assigned to different functional life styles groups (i.e. saprotroph, symbiotroph, arbuscular mycorrhizal (AM), ectomycorrhizal (ECM)) based on published databases (Nguyen et al. 2016; Smith and Read 2008; Sun et al. 2016; Tedersoo et al. 2014; Thormann 2006; Thormann and Rice 2007).

\section{Statistical Analyses}

All statistical analyses were conducted in R. The study was divided into two datasets that were analyzed separately. Dataset 1 including 84 samples treated as low-intensity fire samples. Dataset2 including 48 samples was used to investigate the response of fungal community to high-intensity fire. For each dataset, the data analysis was separately performed by soil depth. Linear mixed models with time since fire as a continuous variable were used to determine the general relationship effects of time since fire on soil properties, fungal copy numbers, fungal diversity and relative abundance of fungal groups with site as a random factor. Time since fire and other variables were log or square root transformed when necessary. Models were fit with the package Ime4 (Bates et al. 2014). Firstly, corrected Akaike information criterion (AICc) was used to identify the best mixed-effects model from linear, quadratic and cubic polynomial models. We then calculated $P$, marginal $\mathrm{R}^{2}\left(\mathrm{R}_{\mathrm{m}}{ }^{2}\right)$ and conditional $\mathrm{R}^{2}\left(\mathrm{R}_{\mathrm{c}}{ }^{2}\right)$ for each best model by the function 'r.squaredGLMM' in MUMIN. Marginal $\mathrm{R}^{2}\left(\mathrm{R}_{\mathrm{m}}{ }^{2}\right)$ represents the variance explained by fixed effects, whereas conditional $R^{2}\left(R_{c}{ }^{2}\right)$ represents the variance explained by both fixed and random effects. Tukey's HSD test with time since fire as categorical variable was used to compare time effects for each time of post-fire. In addition, we used the function 'manyglm' in mvabund (Wang et al. 2012) to test how each OTU varied with the increasing time since fire, focusing on species with $>50 \%$ frequency. Principal Coordinates Analysis (PCOA) was performed in vegan to illustrate the community shifts of fungi along fire stage and soil depths. To quantify the drivers behind fungal community shifts following fire and identify the effects of time since fire on fungal composition when accounting for the spatially nested design and soil heterogeneity, generalized dissimilarity modeling (GDM) (Ferrier et al. 2007) was performed using the gdm package. Due to combusted the complete plant aboveground biomass in our study site (Flanagan et al. 2020), shrub diversity of $15 \mathrm{~d}$ and $71 \mathrm{~d}$ were not surveyed. Therefore, we did not include shrub diversity for low-intensity fire for GDM analysis. PERMANOVA with ADONIS function, ANOSIM (analysis of similarity) and multiple-response permutation procedure (MRPP) with 999 permutations were used to evaluate the significant difference in the community structure between fire stages and peat depths. All of these analyses were conducted using the vegan package with the vegdist, mrpp, mantel.test, envfit, adonis and anosim functions. Linear regression fit with depth as categorical variable was used to determine the relationship between depth and fungal copy number, Shannon diversity, and soil properties for each fire stage.

\section{Results}

\section{Soil Physicochemical Properties}

Regardless of fire intensity, soil total carbon (TC), dissolved organic carbon (DOC) and ammonia concentration $\left(\mathrm{NH}_{4}-\mathrm{N}\right)$ were not affected by time since fire in any horizon, as analyzed by linear mixed-effect models (Table S2). Phenolics in $0-5$ and 6-10 layers exhibited a quadratic relation with time lapses since lowintensity fire, namely, a decrease at $15 \mathrm{~d}\left(\log _{\mathrm{e}}\right.$ (days since fire) $\left.=2.7\right)$ and an increase from $71 \mathrm{~d}$ to $2 \mathrm{y}\left(\right.$ i.e. $\log _{\mathrm{e}}(\mathrm{days}$ since fire) $=4.2$ and 6.6$)$. The pH value also had a significant non-linear relationship with time since low-intensity fire across all soil layers with lowest value at 71d (Figure S3). The response of pH to lowintensity fire lagged behind that of phenolics concentration in top two layers. After high-intensity fire, soil properties below $5 \mathrm{~cm}$ soil layers had similar fluctuation pattern as time progressed for phenolics and $\mathrm{pH}$. Both measures declined through $30 \mathrm{y}$ at $6-10 \mathrm{~cm}$ layer, but uplifted by $30 \mathrm{y}$ at the two layers below $10 \mathrm{~cm}$ depth (Table S2 and Figure S4). 


\section{Fungal Copy Number}

Fungal ITS copies in all soil samples amounted to $10^{8}-10^{9}$ copies per gram of dry soil. Unexpectedly, fungal ITS copies did not significantly change along fire chronosequences across all soil layers regardless of fire intensity (Table 1). Tukey's test also revealed no significant difference between fire stages. The relationships between fungal ITS copy number and $\mathrm{pH}, \mathrm{DOC}, \mathrm{TC}$ and $\mathrm{NH}_{4}-\mathrm{N}$ concentration were stronger in high-intensity-fire sites than in low-intensity-fire sites (Figure S5).

\section{Fungal Community Structure}

Due to ITS1F and ITS4 being too long to pair-end, we analyzed them separately and received similar results (Figure 1 and Figure S1). Therefore, we used the ITS1F for further analysis. A total of 250,983 high quality sequences were obtained after denoising and quality filtering from ITS1F primer. We observed a total of 689 OTUs. The OTUs were classified into six phyla, including Ascomycota, Basidiomycota, Zygomycota, Chytridiomycota, Glomeromycota and Rozellomycota. Ascomycota was the most dominant phylum, followed by Basidiomycota (Figure 1). Archaeorhizomycetes was predominant across all samples with relative abundances ranging from $44 \%$ to $90 \%$.

To better understand the differences in fungal responses to fire, we classified the fungi to different functional groups based on their life traits. A total 689 OTUs were assigned to nine functional groups (Table 2). Across all samples, $37 \%$ of identified fungal OTUs were saprotrophs, and $~ 19 \%$ OTUs were symbiotrophs. For the mycorrhizal OTUs, arbuscular mycorrhizae were the most frequent and abundant, whereas Glomeraceae and Acaulosporaceae are the dominant families of all symbiotrophs. A total 242 of 689 OTUs were assigned to unassigned groups due to its unknown ecological function. Among all unassigned groups, eighty OTUs were identified as Archaeorhizomycetes.

\section{Fungal Community Response to Fire and Other Environmental Factors}

Time since low-intensity fire only had marginal effect on Shannon diversity in $0-5 \mathrm{~cm}$ layer, but not in other layers, as revealed by linear mixed-effect models (Table 1 and Figure 2A). At 0-5 cm depth, Shannon diversity increased at $71 \mathrm{~d}$ after low-intensity fire and then returned to pre-fire level by $2 \mathrm{y}$ (Figure $2 \mathrm{~A}$ ). At high-intensity fire sites, Shannon diversity of $6-10 \mathrm{~cm}$ soil sharply decreased at $5 y$ (Figure 2B), and consistently declined over time in 11-20 cm soil (Figures $2 \mathrm{C}$ and $2 \mathrm{D})$. Among all samples, the Shannon diversity had a weak positive relation to $\mathrm{NH}_{4}-\mathrm{N}\left(\mathrm{R}^{2}=0.05, P=0.001\right)$.

For low-intensity fire, the PCoA plot showed that fungal community varied considerably along the time since fire gradient across all soil depths, and the variation seemed to be strongest in the surface layer $(0-5 \mathrm{~cm})$ (Figures 3A-3D). PERMANOVA, ANOSIM and MRPP analysis showed that fungal communities significantly varied along the soil depths at each low-intensity fire stage (Table 3, Figures S1A and S1C). GDM analysis showed that time since fire was the strongest driver of total fungal community shifts with explaining $18.08 \%$ and $21.75 \%$ of the variance in $0-5 \mathrm{~cm}$ and $6-10 \mathrm{~cm}$ soil depths, respectively (Table 4), although there was a significant distance-decay relationship for total fungi in all low-intensity fire samples (Figure S6A). Below $10 \mathrm{~cm}$ soil depth, the geographical distance was most important driver that explained $>40 \%$ variance (Table 4 ).

As time passed after low-intensity fire, the relative abundance of Archaeorhizomycetes in $0-5 \mathrm{~cm}$ soil decreased significantly from $15 \mathrm{~d}$ to $71 \mathrm{~d}$, and then increased at 2y, while saprotrophs showed an opposite trend (Figures S7A and S7C). At 6-10 cm depth, Archaeorhizomycetes persistently declined but saprotrophs otherwise thrived (Figures S7B and S7D). No significant patterns were observed below $10 \mathrm{~cm}$ soil. Except for a minor decrease at 15d, symbiotrophs are invariant to temporal variables across all soil depths according to linear mixed-effect model (Table 1).

Fungal communities appeared to progress over time after high-intensity fire for every soil depth (Figures 3E-3H). PERMANOVA, ANOSIM and MRPP analysis showed that fungal communities did not vary along the soil depths at each high-intensity fire stage (Table 3, Figures S5B and S5D). The relative abundance of different fungal guilds did not show any significant pattern along fire chronosequence (Table 1). Similar to low-intensity fire samples, there was a significant geographical distance-decay relationship for total fungi among high-intensity fire samples (Figure S6B). Results of GDM analysis showed that total carbon and phenolics were the primary drivers, which explained $12.8 \%$ variance of total fungal community shifts in $0-5 \mathrm{~cm}$, and $18.3 \%$ in $6-10 \mathrm{~cm}$ soil depths (Table 4). Shrub diversity explained less variation across all soil depths than soil properties and geographic distance (Table 4).

\section{Fire-responsive Fungi}

Within each fire intensity, several frequent ( $\geq 50 \%$ ) occurring OTUs significantly correspond to time lapses since fire (Figures 4 and 5 ). Classified as Mortierella genus, OUT6 declined in 6-15 cm soil over time after low-intensity fire. Other OTUs (OTU9, OTU10, OTU11, OTU12, and OTU62), belonging to Archaeorhizomyces spp., exhibit diverse shift patterns along fire chronosequence. For example, OTU10 and 0TU12 steadily declined with time since fire at depth of 6-20 cm. OTU62 increased across all soil depths. In the high-intensity fire, OTU4, OTU11 and 0TU12 belonging to Archaeorhizomyces significantly correlated with time since fire at $0-15 \mathrm{~cm}$ of soil, but not in the same way.

\section{Discussion}

\section{Responses to Low-intensity Fire}

Due to the presence of multiple copies of ribosomal DNA in the genome with copies varied in strains (Lofgren et al. 2019), exact fungal biomass/fungal cell number in soil samples cannot be estimated simply by fungal copy number. Nevertheless, a linear relationship between the number of copies in the ITS region

Page 5/18 
parsed by qPCR and the hyphal length of fungi can be established (Raidl et al. 2005). Therefore, to some extent, it is permissible using fungal copy number to infer biomass/population size (Prevost-Boure et al. 2011) in this study. Our results showed that the fungal copy number remained constant after short-term low-intensity fire. It has been shown that some fungi that survive in spore banks (Glassman et al. 2016) are the beneficiary of low-intensity fire, which may promote a rapid recovery. Another possible explanation was a decrease in soil pH after fire. Lower pH can favor some fungal growth (Pietikainen and Fritze 1995) and counteract the reduction of fungal copy number by heating. This also suggested that any changes in community structure along the fire chronosequence might be due to changes in individual relative abundances rather than to differences in the total number of fungal community among soils (Lee et al. 2017).

Shifts in fungal Shannon diversity and fungal community composition along time since low-intensity fire gradient were pronounced in the surface (0-5 $\mathrm{cm}$ ) layer (Figure 2 and Figure 3), which coincides with other observations in Australia and the United States (Anderson et al. 2007; Brown et al. 2013; Sun et al. 2015). Although fungal Shannon diversity, relative abundance of Archaeorhizomycetes and saprotrophs in surface (0-5 cm) soil shifted after fire from $15 \mathrm{~d}$ to 71d, they returned to pre-fire level at 2y (Figure 2A and Supplementary Figure S7), indicating a high resilience to low-intensity fire. Low-intensity fire increased the relative abundance of Archaeorhizomycetes and induced saprotrophs in surface soil (Figure S7). Previous studies suggest that Archaeorhizomycetes growth depends on root-derived materials (Rosling et al. 2011). Plant root derivatives are the main input of labile soil carbon (Fernandez and Kennedy 2016). Fire combusted the complete plant aboveground biomass in our study site (Flanagan et al. 2020), which may disrupt root derivative production and resulted in loss of Archaeorhizomycetes population. Low-intensity fire along short duration increase the availability of fresh organic matter and nutrients, which in turn stimulate the growth of saprotrophic fungi (Hartmann et al. 2014; Perez-Valera et al. 2019; Sun et al. 2015) in surface layers. Time since low-intensity fire did not affect fungal composition and diversity in soil $>10 \mathrm{~cm}$ depth maybe because damp peaty soils are highly effective in delaying heat penetration (Davies et al. 2010), that fungal communities found refuge below $10 \mathrm{~cm}$ depth during low-intensity fire.

Although dwindled upon burn episode, Archaeorhizomycetes remained the most abundant fungal class, accounting for $48 \%-74 \%$ of total sequences across all fire stages after low-intensity fire. Archaeorhizomycetes represents one of the most ubiquitous lineages of soil fungi and an ancient class of fungi, yet only two species of this class have been identified (Menkis et al. 2014; Rosling et al. 2011; Rosling et al. 2013). Current knowledge showed that Archaeorhizomycetes might have $K$-strategies taxa with plant root-symbiosis (Hewitt et al. 2013; Naranjo-Ortiz and Gabaldon 2019) and markedly slow growth rates (Menkis et al. 2014; Rosling et al. 2011; Rosling et al. 2013). The persistence of dominant Archaeorhizomycetes may provide resilience in the ecological function of a system by alleviating post-disturbance lag times in ecological processes (Hewitt et al. 2013). Several OTUs (such as OTU9, OTU10, OTU11, OTU12, OTU62) belonging to Archaeorhizomycetes significantly varied as a function of time lapse since fire and with differential dominance patterns suggesting its non-linearity trait of responses. However, their ecological roles and interaction with environmental factors are unknown and need further studies.

\section{Responses to High-intensity Fire}

Meta-analyses indicated that the Alaskan boreal forests would take at least a decade, or even up to two and a half decades, to completely shift back to the unburned state after a high-intensity fire (Dooley and Treseder 2012; Holden et al. 2013). In boreal forests, most recent studies suggest that increasing burn severity induced the increment of fungal communities dissimilarity (Whitman et al. 2019). In our sites, the high-intensity fire killed all trees and led to 1-m peat loss. As a result fungal community composition significantly differed from each other which suggests that at least more than three decades are needed for a complete recovery after high-intensity fire in this subtropical shrub peatland. Following a high-intensity wildfire, recovery of soil fungal community came after that of plant community because fungal recovery was more closely related to soil organic matter than aboveground plant community (Dooley and Treseder 2012; Holden et al. 2013). In our study sites, the shrub diversity and the dominant fire tolerant plant recovered quickly (Table S1). Surprisingly, within the same high-intensity fire site, depth have no effect on fungal community composition (Table 3 ) and fungal copy number $(P=0.13$ and $P=0.77$ for $5 y$ and $30 \mathrm{y}$, respectively), indicating high-intensity fire eclipses depth-dependent distribution patterns of the fungal community. It is important to note that $1 \mathrm{~m}$ of peat consuming high-intensity fire may have selected for the well fire-adapted fungi (Reazin et al. 2016) across all studied soil depths. In addition, adaptation to soil nutrient environments is a niche process that can affect many microbial species due to the variance in their ability to break down recalcitrant organic matter (Talbot et al. 2013). Phenolics, one of recalcitrant organic matter, increased with depth in pre-fire site, but had no pattern in 5y and 30y samples. Long duration of high-intensity fire consuming substantial amounts of decay-resistance litter can release a pulse of nutrients (Jauhiainen et al. 2016; Sawyer et al. 2018), in turn, creating more similar soil properties along soil profiles. Within site scale, similar nutrient concentrations may form similar fungal community across soil depths.

\section{Drivers of Succession}

Although geographic distance was an important predictor in fungal community assemblage (Talbot et al. 2014; Yang et al. 2020), low-intensity fire events weaken spatial effects in fungal communities in surface layers (Table 4). Time since low-intensity fire was identified in our study as the strongest driver for fungal composition turnover in the surface layer, which is consistence with reports in cold forest organic horizons (Yang et al. 2020). Time per se is not an environmental factor; rather, it integrates a range of changes, both biotic and abiotic, that occur over time (Cutler et al. 2017). In our studies, time since fire was closely related to soil $\mathrm{pH}$ and phenolics. Progressive changes in these factors are likely to have impact on fungal community structure as well (Cutler et al. 2017).

Not surprisingly, significant distance-decay relationship was also observed in high-intensity fire samples, but this relationship was confounded by substrate effects in our study. Fungal community reassembly after high-intensity fire was strongly linked to differences in post-fire soil properties which determined by site-level variation (Alcaniz et al. 2018; Certini 2005). Furthermore, environmental heterogeneity may affect the distance-decay relationship for fungi (Green et al. 2004). 
The main limitation is that the response pattern to both low-and high-intensity fire were detected from different timelines. Missing multiple short-term time sampling events may affect our detection of fungal community responses to different high-intensity fires (Ludwig et al. 2018). For example, in high-intensity fire, no considerable difference in fungal copy number between three time points (pre-fire, mid-term and long-term history) were detected, while the structure of fungal community varied among different times. Fungal copy number, a fungal biomass proxy, recover faster than fungal community structure, and thus the dynamics of fungal copy number may have been overshadowed due to our missing short-term sampling points. Direct effects of microbes decimated by fire may be no longer viable one year after fire (Whitman et al. 2019). High-intensity burn may result in an immediate reduction in fungal biomass (Holden et al. 2016) and shifts in community structure (Day et al. 2019). Therefore, gaining insights of a long lasting post-fire fungal succession is a must. Nevertheless, we focused on fungal community response to high-intensity fire in the long-term in this study. Few studies have concentrated on long-term (decades-centuries) changes in community composition and structure (Cutler et al. 2017; Yang et al. 2020), but are crucial for understanding the consequences of peat fire management under future climatic change.

Another limitation was that we did not consider post-fire vegetation variation in living shrub biomass. In this study, both low-intensity and high-intensity fire had no significant effect on the relative abundance of symbiotrophic fungi (Table 1). For low-intensity fire, this may be correlated with relatively stable shrub diversity (Table S1). Low-intensity fires resulted in high tree survival and shallow depth of burn in which mycorrhizal colonization and diversity can persist (Pressler et al. 2019). For high-intensity fire, the dynamics of symbiotrophs were not detectable due to missing sampling time point and shrub diversity recovered at $5 y$ (Table S1).

\section{Conclusion}

Our study shows that time since fire, geographic distance and soil characteristic together explained a large proportion of variation in fungal communities, which is strongly dependent on soil horizons and fire intensity. Fungal communities are highly resilient to low-intensity fires, while vulnerable to high-intensity fire in our peatland. Hence, it is likely that the fungal communities recover within low-intensity fire interval in this shrub peatland. High-intensity fire induced a significant community structure shift along the fire chronosequence and eliminated vertical distribution patterns over three decades. Had it not for fungal resilience, future intensified fire events within three decades would further hinder the recovery of soil microbiome and the ecosystem process it regulates (Pressler et al. 2019), including plant communities recovery following fire. Taken together, these results suggest that soils in some subtropical peatlands may have a high capacity to recover themselves following low-intensity fires and, in turn, keep carbon stock stable. This study also improved our understanding on how low-intensity versus high-intensity fires impact soil fungal communities given the mounting size and frequency of fires in peatland under impending climate change.

\section{Conclusion}

Our study shows that time since fire, geographic distance and soil characteristic together explained a large proportion of variation in fungal communities, which is strongly dependent on soil horizons and fire intensity. Fungal communities are highly resilient to low-intensity fires, while vulnerable to high-intensity fire in our peatland. Hence, it is likely that the fungal communities recover within low-intensity fire interval in this shrub peatland. High-intensity fire induced a significant community structure shift along the fire chronosequence and eliminated vertical distribution patterns over three decades. Had it not for fungal resilience, future intensified fire events within three decades would further hinder the recovery of soil microbiome and the ecosystem process it regulates (Pressler et al. 2019), including plant communities recovery following fire. Taken together, these results suggest that soils in some subtropical peatlands may have a high capacity to recover themselves following low-intensity fires and, in turn, keep carbon stock stable. This study also improved our understanding on how low-intensity versus high-intensity fires impact soil fungal communities given the mounting size and frequency of fires in peatland under impending climate change.

\section{Declarations}

\section{Funding}

This work was supported by the US DOE Office of Science, Terrestrial Ecosystem Sciences (DE-SC0012272), the Duke University Wetland Center Endowment, and China Scholarship.

\section{Conflicts of interest}

The authors declare no competing interests.

\section{Data Availability}

Sequence data obtained from this study have been deposited in the NCBI Sequence Read Archive (SRA) with the accession number SRP176379. The sequence data of 30y sites and pre-fire sites were retrieved from our another paper (under review, archived at BioRxiv [doi: https://doi.org/10.1101/2020.04.11.034108], accession number SRP122579).

\section{Authors' contributions}

Conceptualization: J.T., H.W., N.F. and C.J.R.; Funding Acquisition: C.J.R., H.W. and R.V.; Resources: H.W., M.H., C.J.R. and N.F; Investigation: J.T.; Writing Original Draft: J.T., H.W. and C.J.R., Writing - Review \& Editing: J.T., H.W., R.V., M.H., N.F. and C.J.R. 


\section{References}

Abarenkov K, Nilsson RH, Larsson K-H et al. (2010) The UNITE database for molecular identification of fungi - recent updates and future perspectives. New Phytol 186:281-285

Alcaniz M, Outeiro L, Francos M, Ubeda X (2018) Effects of prescribed fires on soil properties: A review. Sci Total Environ 613-614:944-957

Ali AA, Blarquez O,Girardin MP et al. (2012) Control of the multimillennial wildfire size in boreal North America by spring climatic conditions. P Natl Acad Sci USA 109:20966-20970

Allison SD, Martiny JBH (2008) Resistance, resilience, and redundancy in microbial communities. P Natl Acad Sci USA 105:11512-11519

Anderson IC, Bastias BA, Genney DR, Parkin PI, Cairney JWG (2007) Basidiomycete fungal communities in Australian sclerophyll forest soil are altered by repeated prescribed burning. Mycol Res 111:482-486

Barcenas-Moreno G, Baath E (2009) Bacterial and fungal growth in soil heated at different temperatures to simulate a range of fire intensities. Soil Biol Biochem 41:2517-2526

Bates D, Mächler M, Bolker B, Walker S (2014) Fitting linear mixed-effects models using Ime4. ArXiv e-prints arXiv:1406 doi:10.18637/jss.v067.i01

Bengtsson-Palme J et al. (2013) Improved software detection and extraction of ITS1 and ITS2 from ribosomal ITS sequences of fungi and other eukaryotes for analysis of environmental sequencing data. Methods Ecol Evol 4:914-919

Boby LA, Schuur EAG, Mack MC, Verbyla D, Johnstone JF (2010) Quantifying fire severity, carbon, and nitrogen emissions in Alaska's boreal forest. Ecol Appl 20:1633-1647

Bragazza L (2006) A decade of plant species changes on a mire in the italian alps: vegetation-controlled or climate-driven mechanisms? Clim Change 77:415429

Bragazza L, Parisod J, Buttler A, Bardgett RD (2013) Biogeochemical plant-soil microbe feedback in response to climate warming in peatlands. Nat Clim Change 3:273-277

Brown SP, Callaham MA, Oliver AK, Jumpponen A (2013) Deep Ion Torrent sequencing identifies soil fungal community shifts after frequent prescribed fires in a southeastern US forest ecosystem. FEMS Microb Ecol 86:557-566

Caporaso JG et al. (2010) QIIME allows analysis of high-throughput community sequencing data. Nat Methods 7:335-336

Certini G (2005) Effects of fire on properties of forest soils: a review. Oecologia 143:1-10

Clemmensen KE, Finlay RD, Dahlberg A, Stenlid J, Wardle DA, Lindahl BD (2015) Carbon sequestration is related to mycorrhizal fungal community shifts during long-term succession in boreal forests. New Phytol 205:1525-1536

Cole LES, Bhagwat SA, Willis KJ (2019) Fire in the swamp forest: palaeoecological insights into natural and human-induced burning in intact tropical peatlands Front Forests Glob Chang 2:48

Cutler NA, Arroniz-Crespo M, Street LE, Jones DL, Chaput DL, DeLuca TH (2017) Long-term recovery of microbial communities in the boreal bryosphere following fire disturbance. Microb Ecol 73:75-90

Dargie GC, Lewis SL, Lawson IT, Mitchard ETA, Page SE, Bocko YE, Ifo SA (2017) Age, extent and carbon storage of the central Congo Basin peatland complex. Nature 542:86-90

Davies G, Smith A, MacDonald A, Bakker J, Legg C (2010) Fire intensity, fire severity and ecosystem response in heathlands: factors affecting the regeneration of Calluna vulgaris. J Appl Ecol 47:356-365

Day NJ, Dunfiel KE, Johnstone JF et al. (2019) Wildfire severity reduces richness and alters composition of soil fungal communities in boreal forests of western Canada. Glob Chang Biol 25:2310-2324

Dooley SR, Treseder KK (2012) The effect of fire on microbial biomass: a meta-analysis of field studies. Biogeochemistry 109:49-61

Edgar RC (2010) Search and clustering orders of magnitude faster than BLAST. Bioinformatics 26:2460-2461

Fernandez CW, Kennedy PG (2016) Revisiting the 'Gadgil effect': do interguild fungal interactions control carbon cycling in forest soils? New Phytol 209:13821394

Ferrier S, Manion G, Elith J, Richardson K (2007) Using generalized dissimilarity modelling to analyse and predict patterns of beta diversity in regional biodiversity assessment. Divers Distrib 13:252-264 
Fierer N, Jackson JA, Vilgalys R, Jackson RB (2005) Assessment of soil microbial community structure by use of taxon-specific quantitative PCR assays. Appl Environ Microbiol 71:4117-4120

Flanagan NE, Wang H, Winton S, Richardson CJ (2020) Low-severity fire as a mechanism of organic matter protection in global peatlands: Thermal alteration slows decomposition. Glob Chang Biol 26:3930-3946

Glassman SI, Levine CR, DiRocco AM, Battles JJ, Bruns TD (2016) Ectomycorrhizal fungal spore bank recovery after a severe forest fire: some like it hot. ISME J 10:1228-1239

Green JL et al. (2004) Spatial scaling of microbial eukaryote diversity. Nature 432:747-750

Greene DF, Hesketh M, Pounden E (2010) Emergence of morel (Morchella) and pixie cup (Geopyxis carbonaria) ascocarps in response to the intensity of forest floor combustion during a wildfire. Mycologia 102:766-773

Hammill KA, Bradstock RA (2006) Remote sensing of fire severity in the Blue Mountains: influence of vegetation type and inferring fire intensity. Int J Wildland Fire 15:213-226

Hartmann M et al. (2014) Resistance and resilience of the forest soil microbiome to logging-associated compaction. ISME J 8:226-244

Hernandez-Rodriguez M, Oria-de-Rueda JA, Martin-Pinto P (2013) Post-fire fungal succession in a Mediterranean ecosystem dominated by Cistus ladanifer L. For Ecol Manag 289:48-57

Hewitt RE, Bent E, Hollingsworth TN, Chapin FS, Taylor DL (2013) Resilience of Arctic mycorrhizal fungal communities after wildfire facilitated by resprouting shrubs. Ecoscience 20:296-310

Holden SR, Gutierrez A, Treseder KK (2013) Changes in soil fungal communities, extracellular enzyme activities, and litter decomposition across a fire chronosequence in alaskan boreal forests. Ecosystems 16:34-46

Holden SR, Rogers BM, Treseder KK, Randerson JT (2016) Fire severity influences the response of soil microbes to a boreal forest fire. Environ Res Lett 11 doi:Artn 035004

Jauhiainen J, Silvennoinen H, Kononen M, Limin S, Vasander H (2016) Management driven changes in carbon mineralization dynamics of tropical peat. Biogeochemistry 129:115-132

Kettridge N, Turetsky MR, Sherwood JH et al. (2015) Moderate drop in water table increases peatland vulnerability to post-fire regime shift Sci Rep-Uk 5:ARTN 8063

Kranz C, Whitman T (2019) Short communication: Surface charring from prescribed burning has minimal effects on soil bacterial community composition two weeks post-fire in jack pine barrens. Appl Soil Ecol 144:134-138

Langner A, Siegert F (2009) Spatiotemporal fire occurrence in Borneo over a period of 10 years. Glob Chang Biol 15:48-62

Lee SH, Sorensen JW, Grady KL, Tobin TC, Shade A (2017) Divergent extremes but convergent recovery of bacterial and archaeal soil communities to an ongoing subterranean coal mine fire. ISME J 11:1447-1459

Lofgren LA, Uehling JK, Branco S, Bruns TD, Martin F, Kennedy PG (2019) Genome-based estimates of fungal rDNA copy number variation across phylogenetic scales and ecological lifestyles. Mol Ecol 28:721-730

Ludwig SM, Alexander HD, Kielland K, Mann PJ, Natali SM, Ruess RW (2018) Fire severity effects on soil carbon and nutrients and microbial processes in a Siberian larch forest. Glob Chang Biol 24:5841-5852

Lundberg DS, Yourstone S, Mieczkowski P, Jones CD, Dangl JL (2013) Practical innovations for high-throughput amplicon sequencing. Nat Methods 10: 9991002

Martin-Pinto P, Vaquerizo W, Penalver F, Olaizola J, Oria-de-Rueda JA (2006) Early effects of a wildfire on the diversity and production of fungal communities in Mediterranean vegetation types dominated by Cistus ladanifer and Pinus pinaster in Spain. For Ecol Manag 225:296-305

Menkis A, Urbina H, James TY, Rosling A (2014) Archaeorhizomyces borealis sp. nov. and a sequence-based classification of related soil fungal species. Fungal Biol-Uk 118:943-955

Naranjo-Ortiz MA, Gabaldon T (2019) Fungal evolution: major ecological adaptations and evolutionary transitions. Biol Rev 94:1443-1476

Neary DG, Klopatek CC, DeBano LF, Ffolliott PF (1999) Fire effects on belowground sustainability: a review and synthesis. For Ecol Manage 122:51-71 doi:Doi Nguyen NH et al. (2016) FUNGuild: An open annotation tool for parsing fungal community datasets by ecological guild; Fungal Ecol 20:241-248

Oliver AK, Callaham MA, Jumpponen A (2015) Soil fungal communities respond compositionally to recurring frequent prescribed burning in a managed southeastern US forest ecosystem. For Ecol Manag 345:1-9 
Pellegrini AFA et al. (2018) Fire frequency drives decadal changes in soil carbon and nitrogen and ecosystem productivity. Nature 553:194-198

Perez-Valera E, Goberna M, Verdu M (2019) Fire modulates ecosystem functioning through the phylogenetic structure of soil bacterial communities. Soil Biol Biochem 129:80-89

Phillips RP, Brzostek E, Midgley MG (2013) The mycorrhizal-associated nutrient economy: a new framework for predicting carbon-nutrient couplings in temperate forests. New Phytol 199:41-51

Pietikainen J, Fritze H (1995) Clear-cutting and prescribed burning in coniferous forest - comparison of effects on soil fungal and total microbial biomass, respiration activity and nitrification. Soil Biol Biochem 27:101-109

Pressler Y, Moore JC, Cotrufo MF (2019) Belowground community responses to fire: meta-analysis reveals contrasting responses of soil microorganisms and mesofauna. Oikos 128:309-327

Prevost-Boure NC et al. (2011) Validation and application of a pcr primer set to quantify fungal communities in the soil environment by real-time quantitative PCR. PLOS One 6:ARTN e24166

Raidl S, Bonfigli R, Agerer R (2005) Calibration of quantitative real-time TaqMan PCR by correlation with hyphal biomass and ITS copies in mycelia of Piloderma croceum. Plant Biol 7:713-717

Reazin C, Morris S, Smith JE, Cowan AD, Jumpponen A (2016) Fires of differing intensities rapidly select distinct soil fungal communities in a Northwest US ponderosa pine forest ecosystem. For Ecol Manag 377:118-127

Rosling A et al. (2011) Archaeorhizomycetes: unearthing an ancient class of ubiquitous soil fungi. Science 333:876-879

Rosling A, Timling I, Taylor DL (2013) Archaeorhizomycetes: Patterns of Distribution and Abundance in Soil. In: Horwitz AB, Mukherjee KP, Mukherjee M, Kubicek PC (eds) Genomics of soil- and plant-associated fungi. Springer Berlin Heidelberg, Berlin, Heidelberg, pp 333-349.

Sawyer R, Bradstock R, Bedward M, Morrison RJ (2018) Fire intensity drives post-fire temporal pattern of soil carbon accumulation in Australian fire-prone forests. Sci Total Environ 610-611:1113-1124

Semenova-Nelsen TA, Platt WJ, Patterson TR, Huffman J, Sikes BA (2019) Frequent fire reorganizes fungal communities and slows decomposition across a heterogeneous pine savanna landscape. New Phytol 224:916-927

Smith SE, Read D (2008) Mycorrhizal Symbiosis. Third Edition edn. Academic Press, London, UK

Sun $\mathrm{H}$ et al. (2015) Fungal community shifts in structure and function across a boreal forest fire chronosequence. Appl Environ Microbiol 81:7869-7880

Sun $\mathrm{H}$, Terhonen E, Kovalchuk A et al. (2016) Dominant tree species and soil type affect the fungal community structure in a boreal peatland forest. Appl Environ Microbiol 82:2632-2643

Talbot JM et al. (2013) Independent roles of ectomycorrhizal and saprotrophic communities in soil organic matter decomposition Soil Biol Biochem 57:282291 doi:10.1016/j.soilbio.2012.10.004

Talbot JM, Bruns TD, Taylor JW et al. (2014) Endemism and functional convergence across the North American soil mycobiome. P Natl Acad Sci USA $111: 6341-6346$

Tedersoo L, Bahram M, Polme S et al. (2014) Global diversity and geography of soil fungi. Science 346:1078-1256688-1

Thormann MN (2006) Diversity and function of fungi in peatlands: A carbon cycling perspective. Can J Soil Sci 86:281-293

Thormann MN, Rice AV (2007) Fungi from peatlands. Fungal Divers 24:241-299

Treseder KK, Mack MC, Cross A (2004) Relationships among fires, fungi, and soil dynamics in Alaskan Boreal. For Ecol Appl 14:1826-1838

Turetsky M, Wieder K, Halsey L, Vitt D (2002) Current disturbance and the diminishing peatland carbon sink. Geophys Res Lett 29:Artn 1526

Turetsky MR, Benscoter B, Page S, Rein G, van der Werf GR, Watts A (2015) Global vulnerability of peatlands to fire and carbon loss. Nat Geosci 8:11-14

Wang Y, Naumann U, Wright ST, Warton DI (2012) mvabund- an R package for model-based analysis of multivariate abundance data. Methods Ecol Evol 3:471-474

White TJ, Bruns TD, Lee SB, Taylor JW (1990) Amplification and direct sequencing of fungal ribosomal RNA genes for phylogenetics. In: PCR Protocols, a Guide to Methods and Applications, 315-322

Whitman T, Whitman E, Woolet J, Flannigan MD, Thompson DK, Parisien M-A (2019) Soil bacterial and fungal response to wildfires in the Canadian boreal forest across a burn severity gradient. Soil Biol Biochem 138:107571

Winsborough C, Basiliko N (2010) Fungal and bacterial activity in northern peatlands. Geomicrobiol J 27:315-320

Page 10/18 
Xiang XJ, Gibbons SM, Yang J, Kong JJ, Sun RB, Chu HY (2015) Arbuscular mycorrhizal fungal communities show low resistance and high resilience to wildfire disturbance. Plant Soil 397:347-356

Yang T, Tedersoo L, Lin X et al. (2020) Distinct fungal successional trajectories following wildfire between soil horizons in a cold-temperate forest. New Phytol 227:572-587

\section{Tables}

Table 1. Results of linear mixed-effects models for the effects of fire stage on fungal diversity, fungal copy number and relative abundances of fungal guilds. Site is a random factor under low- and high-intensity fire. Significant $P$ values are in bold.

\begin{tabular}{|c|c|c|c|c|c|c|c|c|c|c|c|c|}
\hline & $0-5 \mathrm{~cm}$ & & & $6-10 \mathrm{~cm}$ & & & $11-15 \mathrm{~cm}$ & & & $16-20 \mathrm{cn}$ & & \\
\hline & $P_{\text {adj }}$ & $\mathrm{R}_{\mathrm{m}}^{2}$ & $\mathrm{R}_{\mathrm{c}}{ }^{2}$ & $P_{\text {adj }}$ & $\mathrm{R}_{\mathrm{m}}^{2}$ & $\mathrm{R}_{\mathrm{c}}{ }^{2}$ & $P_{\text {adj }}$ & $\mathrm{R}_{\mathrm{m}}^{2}$ & $\mathrm{R}_{\mathrm{c}}{ }^{2}$ & $P_{\text {adj }}$ & $\mathrm{R}_{\mathrm{m}}^{2}$ & $\mathrm{R}_{\mathrm{c}}^{2}$ \\
\hline \multicolumn{13}{|l|}{ Low-intensity fire } \\
\hline $\log _{\mathrm{e}}$ (fungal copy number) & 0.74 & 0.01 & 0.005 & 0.10 & 0.07 & 0.67 & 0.06 & 0.15 & 0.16 & 0.83 & 0.00 & 0.56 \\
\hline Shannon diversity & $0.050(Q)$ & 0.31 & 0.26 & 0.50 & 0.01 & 0.60 & 0.10 & 0.05 & 0.69 & 0.34 & 0.02 & 0.76 \\
\hline Fungal Richness & 0.90 & 0.00 & 0.40 & 0.90 & 0.01 & 0.10 & 0.82 & 0.00 & 0.50 & 0.59 & 0.01 & 0.43 \\
\hline Archaeorhizomycetes & $0.05(Q)$ & 0.16 & 0.40 & $0.01(\mathrm{~L})$ & 0.25 & 0.36 & 0.07 & 0.09 & 0.63 & 0.91 & 0.00 & 0.66 \\
\hline Saprotroph & $0.05(Q)$ & 0.10 & 0.24 & $0.001(L)$ & 0.33 & 0.35 & 0.29 & 0.05 & 0.39 & 0.34 & 0.03 & 0.64 \\
\hline Symbitroph & 0.27 & 0.06 & 0.06 & 0.16 & 0.08 & 0.43 & 0.70 & 0.01 & 0.51 & 0.18 & 0.07 & 0.52 \\
\hline ECM fungi & 0.19 & 0.08 & 0.08 & 0.31 & 0.05 & 0.27 & 0.87 & 0.001 & 0.22 & 0.41 & 0.04 & 0.20 \\
\hline AM fungi & 0.81 & 0.00 & 0.00 & 0.14 & 0.10 & 0.38 & 0.38 & 0.02 & 0.67 & 0.14 & 0.07 & 0.63 \\
\hline \multicolumn{13}{|l|}{ High intensity fire } \\
\hline $\log _{e}$ (fungal copy number) & 0.23 & 0.22 & 0.71 & 0.07 & 0.64 & 0.92 & 0.87 & 0.01 & 0.44 & 0.51 & 0.05 & 0.25 \\
\hline Shannon diversity & 0.38 & 0.07 & 0.09 & $0.000(Q)$ & 0.47 & 0.50 & $0.005(L)$ & 0.44 & 0.44 & $0.01(L)$ & 0.22 & 0.34 \\
\hline Fungal Richness & 0.21 & 0.19 & 0.47 & 0.26 & 0.18 & 0.55 & 0.11 & 0.15 & 0.20 & 0.94 & 0.00 & 0.85 \\
\hline Archaeorhizomycetes & 0.90 & 0.00 & 0.54 & 0.49 & 0.10 & 0.77 & 0.54 & 0.08 & 0.75 & 0.80 & 0.02 & 0.86 \\
\hline Saprotroph & 0.96 & 0.01 & 0.52 & 0.63 & 0.03 & 0.25 & 0.50 & 0.09 & 0.66 & 0.64 & 0.06 & 0.94 \\
\hline Symbitroph & 0.42 & 0.13 & 0.79 & 0.32 & 0.16 & 0.59 & 0.41 & 0.11 & 0.53 & 0.74 & 0.02 & 0.81 \\
\hline ECM fungi & 0.31 & 0.18 & 0.69 & 0.27 & 0.11 & 0.16 & 0.35 & 0.16 & 0.68 & 0.58 & 0.07 & 0.68 \\
\hline AM fungi & 0.65 & 0.04 & 0.54 & 0.38 & 0.15 & 0.70 & 0.50 & 0.07 & 0.43 & 0.96 & 0.00 & 0.76 \\
\hline
\end{tabular}

The letter in parentheses indicated the best fitted model. $P_{\text {adj; }}, P$ values after adjustment based on Benjamini-Hochberg procedure; $R_{m}{ }^{2}$, the variance explained by fixed effects; $\mathrm{R}_{\mathrm{C}}{ }^{2}$, the variance explained by both fixed and random effects. TC: Total Carbon; DOC: Disscolve Oragnic Carbon; $\mathrm{NH}_{4}-\mathrm{N}$ : ammonia; $\mathrm{Q}$ : Quadratic fit; L: Linear fit.

Table 2. Assignments of 689 fungal operational taxonomic units (OTUs) to functional groups according to FUNGuild. For each functional group, the number of taxa and number of OTUs is shown. All functional groups taxa were assigned at the genus level. 


\begin{tabular}{|lll|}
\hline Functional group & No. taxa & No. OTUs \\
\hline Saprotrophs & 105 & 255 \\
\hline Biotrophs & 39 & 58 \\
\hline Symbiotroph/Lichenized & 6 & 9 \\
\hline Symbiotroph/ErM & 1 & 7 \\
\hline Symbiotroph/EcM & 22 & 35 \\
\hline Symbiotroph/AM & 42 & 62 \\
\hline Other Symbiotroph & 12 & 21 \\
Unassigned & 240 & 242 \\
Archaeorhizomycetes & 80 & 80 \\
\hline Total & 467 & 689 \\
\hline
\end{tabular}

ErM: Ericoid Mycorrhizas; EcM: Ectomycorrhizas; AM: Arbuscular Mycorrhizas

Table 3. The effect of depth on fungal community structure in each fire stages. Significant $P$ values are in bold.

\begin{tabular}{|c|c|c|c|c|c|c|}
\hline \multirow{3}{*}{$\begin{array}{l}\text { Fire stage } \\
\text { UD }\end{array}$} & \multicolumn{2}{|c|}{ ANOSIM } & \multicolumn{2}{|c|}{ ADONIS } & \multicolumn{2}{|c|}{ MRPP } \\
\hline & \multicolumn{2}{|l|}{$\mathrm{R}$} & \multirow{2}{*}{$\begin{array}{l}R^{2} \\
0.11\end{array}$} & \multirow{2}{*}{$\begin{array}{l}P \\
\quad 0.008\end{array}$} & \multirow{2}{*}{$\begin{array}{l}\delta \\
0.76\end{array}$} & \multirow{2}{*}{$\begin{array}{l}P \\
0.008\end{array}$} \\
\hline & 0.23 & 0.002 & & & & \\
\hline \multicolumn{7}{|c|}{ Low-intensity fire } \\
\hline $15 d$ & 0.12 & 0.050 & 0.11 & 0.002 & 0.76 & 0.040 \\
\hline $71 d$ & 0.31 & 0.002 & 0.12 & 0.001 & 0.77 & 0.002 \\
\hline $2 y$ & 0.18 & 0.040 & 0.18 & 0.020 & 0.67 & 0.040 \\
\hline \multicolumn{7}{|c|}{ High-intensity fire } \\
\hline $5 y$ & 0.01 & 0.930 & 0.12 & 0.620 & 0.68 & 0.870 \\
\hline $30 y$ & 0.12 & 0.100 & 0.24 & 0.060 & 0.46 & 0.120 \\
\hline
\end{tabular}

Multi response permutation procedure analysis (MRPP), analysis of similarity (ANOSIM) and analysis of dissimilarity (ADONIS) were used to test the effect of soil depths on fungal community based on Bray-Curtis distances. Numerical values represent probability scores (i.e., $P$ values) resulting from each test. $P<$ 0.05 are bolded to highlight significant and near-significant results.

Table 4. The drivers of fungal community shifts in a fire chronosequence determined by generalized dissimilarity modeling (GDM). The strongest drivers are in bold. 


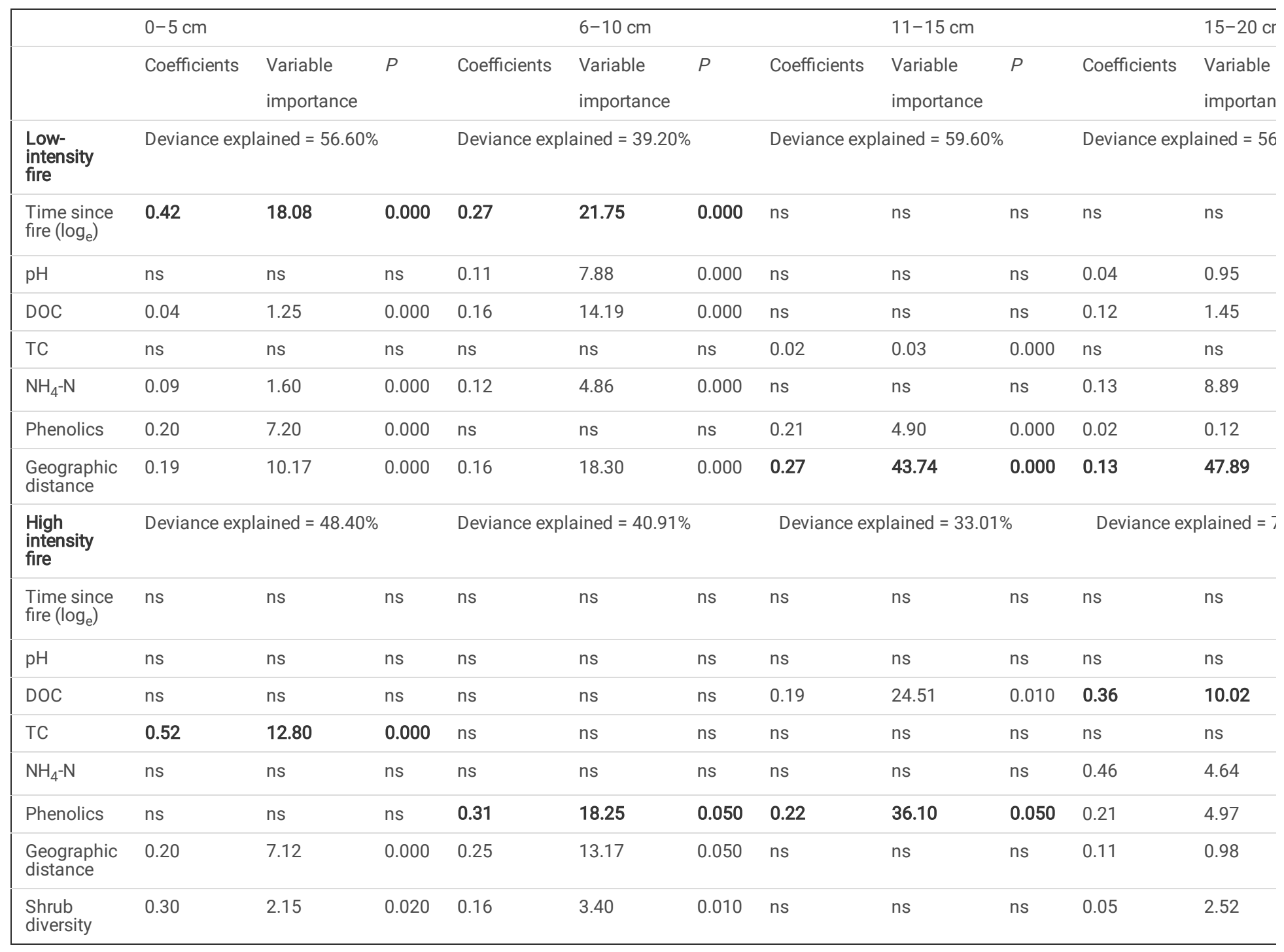

ns, not significant. TC: Total Carbon; DOC: Dissolve Organic Carbon; $\mathrm{NH}_{4}-\mathrm{N}$ : ammonia;

\section{Figures}



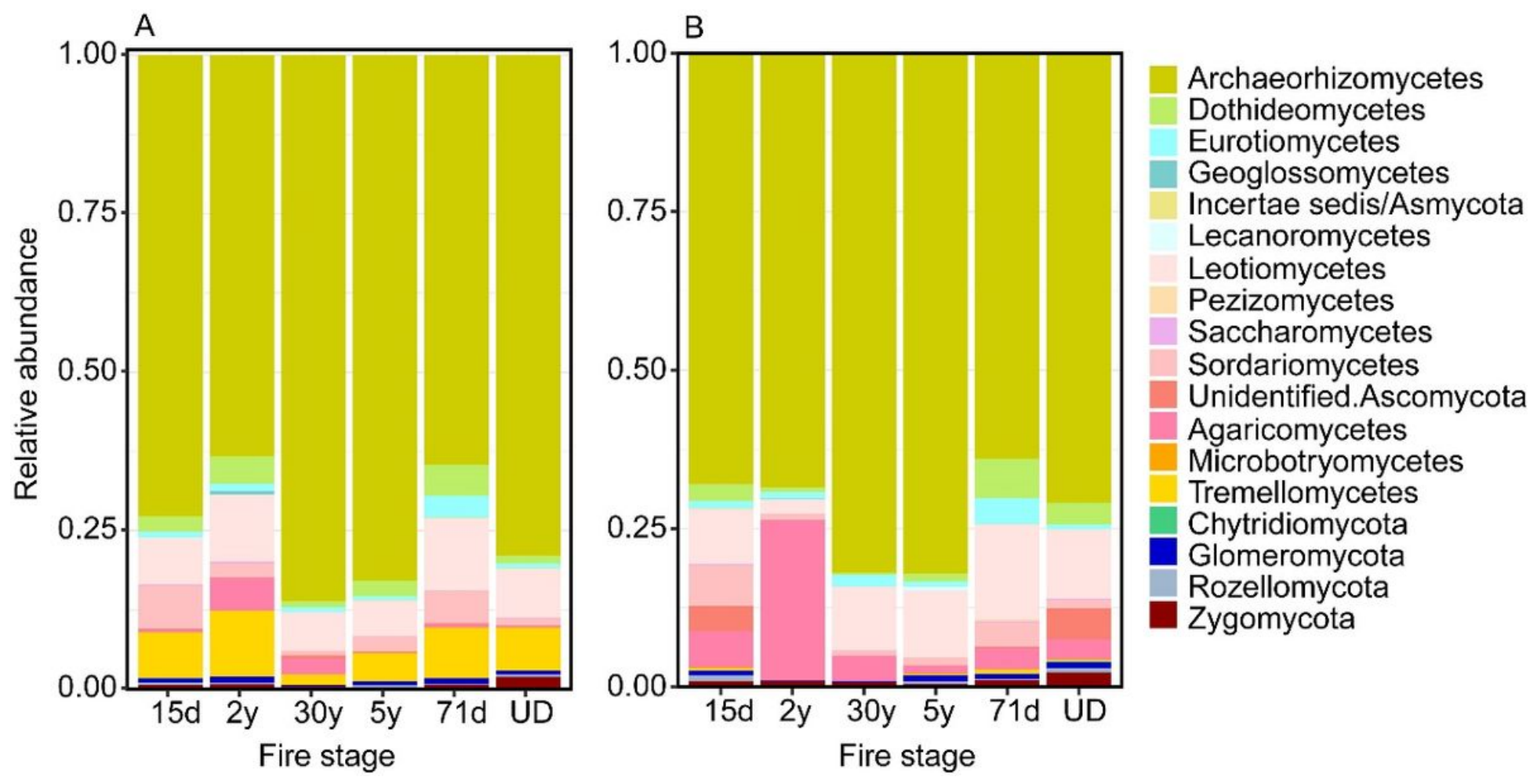

Figure 1

Distribution of phylogenetic groups in each fire stage based on ITS1F and ITS4 primers, respectively. (A) ITS1F primer; (B) ITS4 primer. Fire stage: 30 years post-fire (30y); 5 years post-fire (5y); 2 years post-fire (2y); 71 days post-fire (71d); 15 days post-fire (15d); undisturbed (UD). 

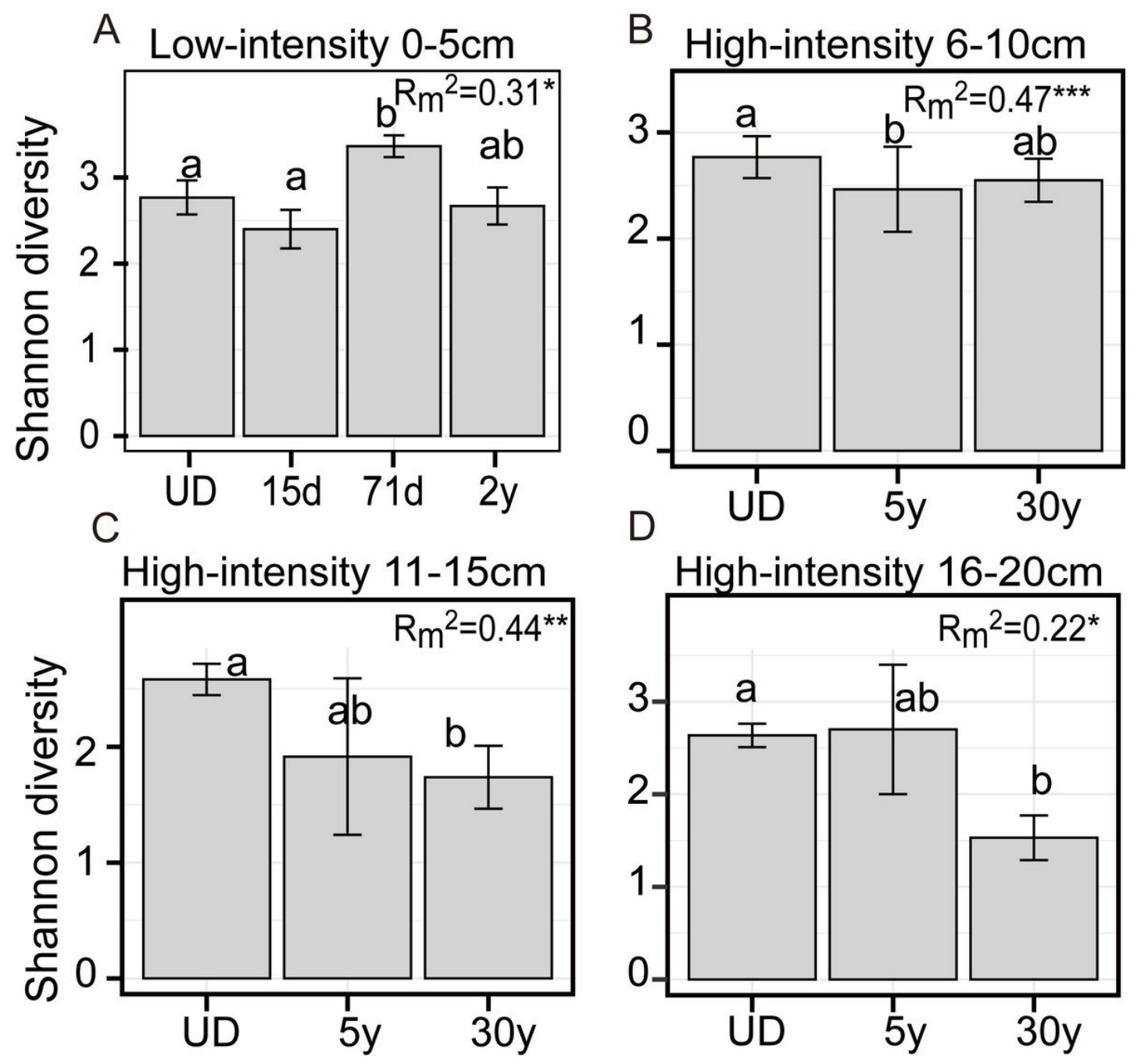

Figure 2

The variation of fungal Shannon diversity along time since fire. A: low-intensity fire; B-D: high-intensity fire. Statistical significance effect of time since fire was determined using a linear mixed-effects model (where sampling sites as random factors). Only the significant relationships are shown. Marginal R2 (Rm2) represents the variance explained by fixed effects. Significant differences are reported as *, $P<0.05 ; * \star, P<0.01$; ***, $P<0.001$. Fungal Shannon diversity for each fire stage at each soil layer is also given as the mean \pm SE derived from 3 or 6 replicate measurements. Bars with the same letter were not significantly different in Tukey's HSD test reported from one-way ANOVA. Fire stage: 30 years post-fire (30y); 5 years post-fire (5y); 2 years post-fire (2y); 15 days post-fire (15d); 71 days post-fire (71d); undisturbed (UD). 

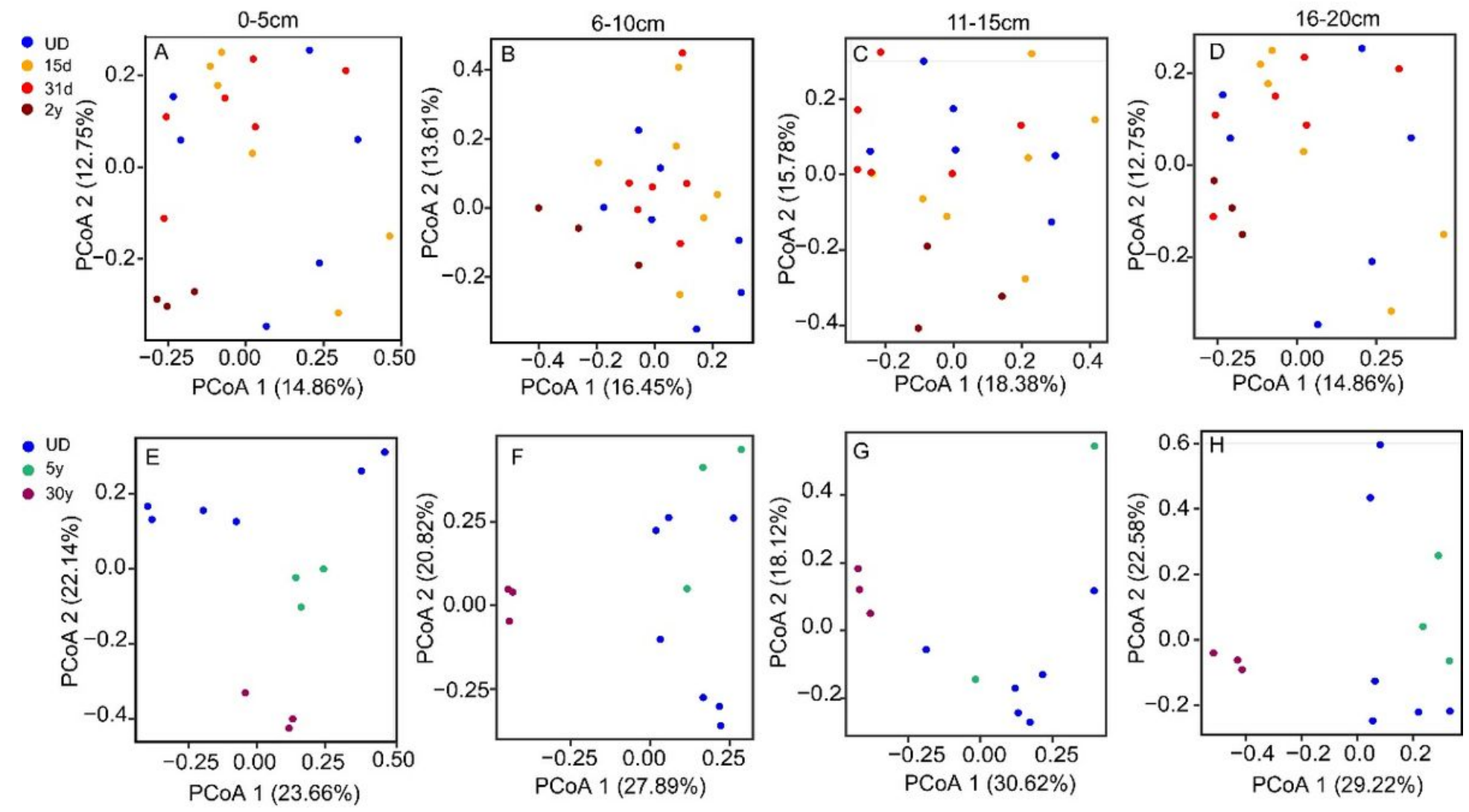

Figure 3

Principal coordinate analysis (PCoA) ordinations of Bray-Curtis similarities calculated based on relative OTU abundances for each soil depth. Variance explained by each PCoA axis is given in parentheses. A-D: Low intensity fire regime; E-H: Severe fire regime. Fire stage: 30 years post-fire (30y); 5 years post-fire (5y); 2 years post-fire (2y); 15 days post-fire (15d); 71 days post-fire (71d); undisturbed (UD). 

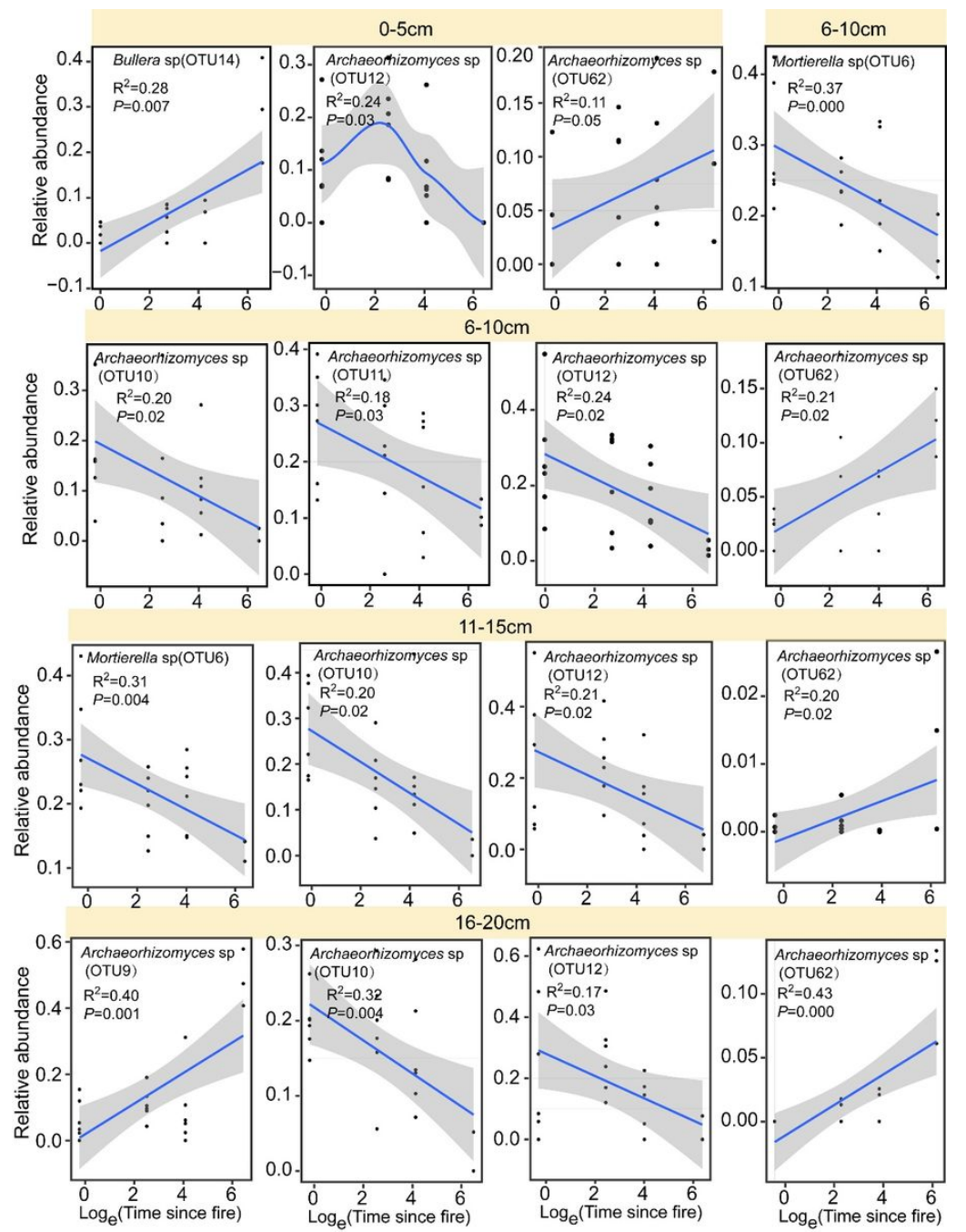

\section{Figure 4}

Selected fire-responsive fungal OTUs along time since fire after low-intensity fire. The variation of each soil fungal taxa along time-since-fire was determined by model-based analysis of multivariate abundance data. 

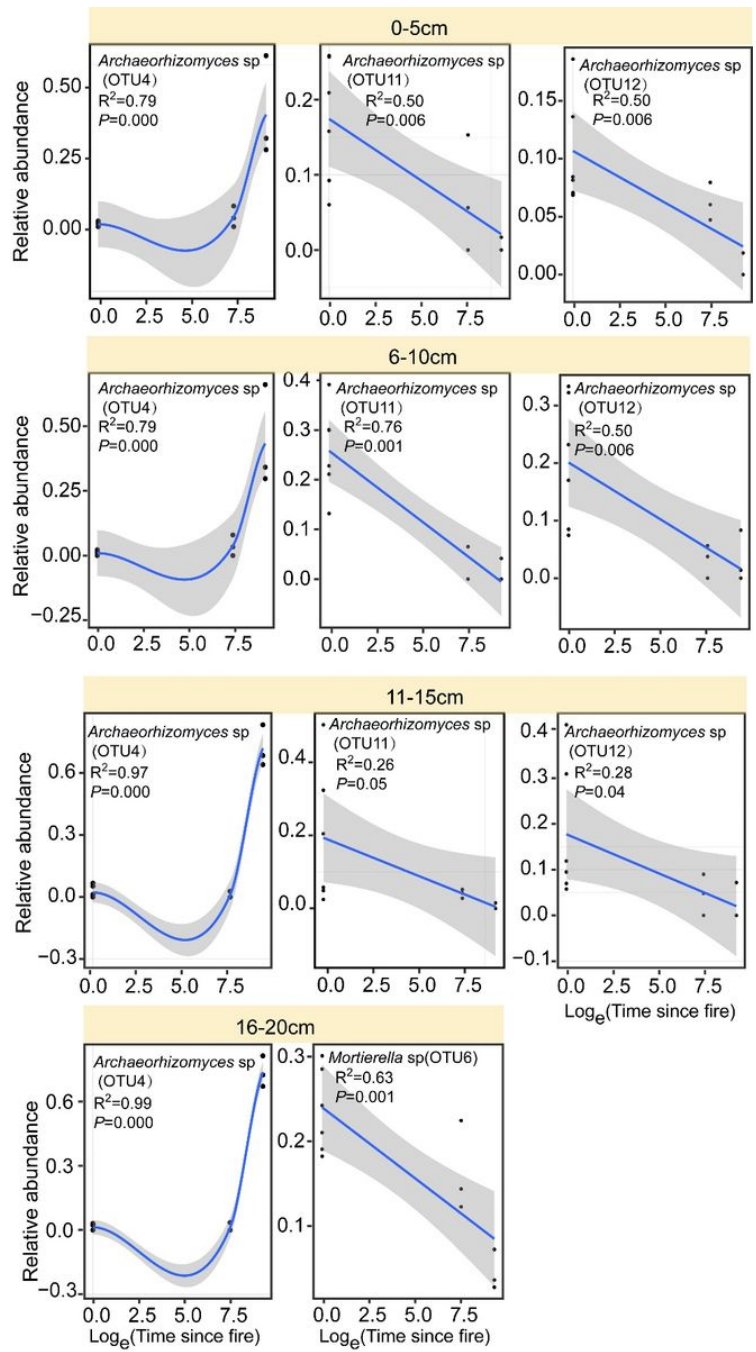

\section{Figure 5}

Selected fire-responsive fungal OTUs along time since fire after high-intensity fire. The variation of each soil fungal taxa along time-since-fire was determined by model-based analysis of multivariate abundance data.

\section{Supplementary Files}

This is a list of supplementary files associated with this preprint. Click to download.

- Suppledatarevised1221.docx 